\title{
HUBUNGAN TINGKAT PENDIDIKAN IBU DAN PERSONAL HYGIENE DENGAN KEJADIAN PEDICULOSIS CAPITIS
}

\author{
The Correlation Between Mother Education and Personal Hygiene with Incidence of \\ Pediculosis capitis
}

\author{
Amilatus Sholihah ${ }^{1}$, Diah Fauzia Zuhroh ${ }^{2}$ \\ ${ }^{1,2}$ Program Studi Ilmu Keperawatan Universitas Muhammadiyah Gresik \\ Alamat Korespondensi : Prodi Ilmu Keperawatan dan Ners \\ Jl. Proklamasi No. 54 Gresik \\ email: fauzia_diah@umg.ac.id
}

\begin{abstract}
ABSTRAK
Pediculosis capitis adalah infeksi kulit atau rambut kepala yang disebabkan oleh infestasi pediculus humanus var. capitis. Prevalensi penyakit ini cukup tinggi terutama pada siswi. Penyakit ini disebabkan oleh banyak faktor. Diantaranya adalah tingkat pendidikan ibu dan personal hygiene. Penelitian bertujuan untuk mengetahui hubungan tingkat pendidikan ibu dan personal hygiene dengan kejadian pediculosis capitis pada siswi di SDN Bulangan Branta Pegantenan Kabupaten Pamekasan Madura.

Penelitian ini merupakan observasional analitik dengan pendekatan cross sectional. Metode pengambilan sampel dengan teknik proportional sampling. Populasi dalam penelitian ini adalah siswi dari kelas dua sampai kelas enam di SDN Bulangan Branta Pegantenan Kabupaten Pamekasan, dengan jumlah sampel 30 siswi. Metode pengambilan data menggunakan kuesioner dan observasi kemudian dianalisis menggunakan uji statistik korelasi lambda dengan tingkat signifikasi $(\alpha)=0,05$.

Dari hasil uji korelasi lambda hubungan tingkat pendidikan ibu dengan kejadian pediculosis capitis diperoleh nilai signifikasi $\mathrm{p}<\alpha(0.032<0.05)$ dan hubungan personal hygiene dengan kejadian pediculosis capitis diperoleh hasil signifikasi $\mathrm{p}<\alpha(0.003<0.05)$.

Ada hubungan tingkat pendidikan ibu dan personal hygiene dengan kejadian pediculosis capitis pada siswi di SDN Bulangan Branta Pegantenan Kabupaten Pamekasan Madura.
\end{abstract}

\section{Kata kunci : Pendidikan, personal hygiene, pediculosis capitis}

\section{ABSTRACT}

Pediculosis capitis is an infection of the skin or scalp hair caused by infestation of pediculus humanus var capitis.. The prevalence of this disease is high especially in students. The disease is caused by many factors. Among them are the mother's education level and personal hygiene. The research aims to know the relationship of maternal education level and personal hygiene with pediculosis capitis in schoolgirl in SDN Bulangan Branta Pegantenan Pamekasan Madura.

This study is observational, analytic approach of cross sectional. Method of sampling with proportional sampling techniques. The population in this study are students from grade two to grade six at SDN Bulangan Branta Pegantenan Pamekasan, with a total sample of 30 students. Data retrieval method using questionnaires and observations are then analyzed using statistical tests of correlation with the level of significance of the lambda $(\alpha)(0.05$.

Correlation of test results from the lambda's relationship with the mother's level of education pediculosis capitis retrieved the value significance of $p<\alpha(0.032<0.05)$ and personal hygiene with pediculosis capitis obtained results of significance $p<\alpha(0.003<0.05)$.

There is a relationship of maternal education level and personal hygiene with pediculosis capitis in schoolgirl in SDN Bulangan Branta Pegantenan Pamekasan Madura.

\section{Keywords : Education, personal hygiene, pediculosis capitis}




\section{PENDAHULUAN}

Kutu kepala (pediculus humanus capitis) merupakan ektoparasit obligat yang menyerang kulit kepala manusia. Pediculosis capitis hidup dan memperoleh makanan, kehangatan serta kelembapan dari tubuh manusia (Yousufi et al, 2012 dalam Nindia 2016). Pediculosis capitis perlu mendapatkan perhatian karena penyakit ini menyerang siapa saja tanpa mengenal jenis kelamin. Perempuan adalah populasi yang sering terinfeksi terutama pada perempuan usia sekolah dasar karena pada umumnya perempuan berambut panjang dari pada laki-laki, sehingga membutuhkan perawatan yang baik dan. Rambut yang kotor, lembab, jarang disisir dan dikeramas merupakan tempat yang disukai untuk berkembang biak pediculus humanus capitis (Zulinda, 2010). Pediculosis capitis menimbulkan banyak masalah diantaranya adalah dikucilkan oleh orang lain, kurangnya rasa percaya diri, kualitas tidur jadi menurun, dan konsentrasi belajar terganggu akibat rasa gatal bahkan dapat menyebabkan anemia yang mengakibatkan anak menjadi lesu, mengantuk di kelas, dan mempengaruhi kinerja belajar dan fungsi kognitif.

Tingkat pendidikan ibu berpengaruh pada frekuensi kejadian pediculosis capitis. Penelitian yang dilakukan oleh Zulinda, et al (2010) berpendapat bahwa pendidikan yang rendah pada ibu berhubungan dengan kejadian pediculosis capitis. Ibu yang berpendidikan rendah berisiko 3,9 kali lebih besar memiliki anak yang terinfeksi pediculosis capitis dibandingkan dengan ibu berpendidikan tinggi.
Penyakit akibat infeksi pediculosis capitis masih menjadi masalah, namun infeksi ini masih dikategorikan sebagai penyakit yang terabaikan terutama pada negara miskin dan negara-negara berkembang. Penelitian yang dilakukan oleh Nindia (2016) menyatakan bahwa tingkat prevalensi pediculosis capitis diseluruh dunia masih cukup tinggi yaitu mencapai $0,7-59 \%$, bahkan prevalensi yang sangat tinggi dilaporkan lebih dari $70 \%$ di negara Pakistan pada tahun 2015.

Karimah et al, (2016) dalam penelitiannya menyebutkan bahwa prevalensi pediculosis capitis dari 123 subjek penelitian yang dilakukan di Jatinagor, Sumedang, Jawa Barat masih cukup tinggi diantaranya terjadi pada siswa dengan ibu lulus sekolah dasar yaitu sebanyak (60\%). Siswa dengan ibu lulus sekolah dasar memiliki prevalensi tertinggi, sementara siswa dengan ibu lulus dari universitas memiliki prevalensi terendah. Karena itu tingkat pendidikan orang tua khususnya ibu sangat berpengaruh terhadap personal hygiene siswa. Studi di Iran menunjukan prevalensi tertinggi pediculosis capitis $2,3 \%$ diantaranya adalah siswa dengan ibu lulus Sekolah Dasar dan Sekolah Menengah Pertama. Selain itu, siswa dengan ibu lulus dari universitas memiliki prevalensi terendah yaitu $0,2 \%$.

Studi pendahuluan yang dilakukan pada 10 siswa di SDN Bulangan Branta Pegantenan Pamekasan, diantaranya 6 siswa (60\%) terinfeksi pediculus humanus capitis, sedangkan 4 siswa (40\%) tidak terinfeksi pediculus humanus capitis. Dari 6 siswa yang terinfeksi pediculus humanus capitis 
mempunyai nilai raport lebih rendah dibandingkan dengan siswa yang tidak terinfeksi dengan angka nilai rata-rata 63,5\%, sedangkan 4 siswa (40\%) yang tidak terinfeksi pediculus humanus capitis mempunyai nilai yang lebih tinggi dengan nilai rata-rata $71,3 \%$.

Salah satu penyebab pediculosis capitis pada perempuan usia sekolah dasar adalah personal hygiene yang kurang, karena pada umumnya perempuan usia sekolah dasar belum mampu mempraktikkan personal hygiene dengan baik dan masih bergantung sepenuhnya pada orang tua terutama ibu. Ibu merupakan guru pertama dalam mendidik anak khusunya dalam hal kebersihan. Cara merawat dan menididik anak tergantung pada tingkat pendidikan ibu karena ibu adalah seseoang yang mendukung untuk kebersihan dalam keluarga tersebut, ibu yang berpendidikan menengah ke atas akan lebih mudah menerima dan menyerap informasi yang didapat sehingga ibu berupaya untuk mencegah agar anak tidak mudah terinfeksi, lain halnya dengan ibu yang berpendidikan rendah. Ibu yang berpendidikan rendah cenderung tidak perduli dengan informasi yang diterima sehingga kurang mampu untuk berkomunikasi.

Personal hygiene merupakan perilaku perawatan diri indvidu mempertahankan kesehatannya, oleh karena itu personal hygiene termasuk ke dalam tindakan pencegahan primer yang spesifik. Personal hygiene menjadi aspek yang penting menjaga kesehatan individu karena personal hygiene yang baik akan meminimalkan masuknya mikroorganisme yang ada di mana-mana dan pada akhirnya mencegah seseorang terkena penyakit. Oleh karena itu diperlukan tindakan intervensi baik dari orang tua maupun guru disekolah untuk pendidikan dan penyuluhan mengenai personal hygiene yang dibantu oleh pihak puskesmas terkait melalui program Usaha Kesehatan Sekolah (UKS).

\section{METODE}

Jenis penelitian ini adalah observasional analitik karena tidak memerlukan perlakuan khusus dari peneliti dan pengamatan dilakukan langsung kepada responden dengan menyebarkan koesioner untuk dianalisis. Desain penelitian ini menggunakan pendekatan cross sectional, yaitu jenis penelitian yang menekankan waktu pengukuran/observasi data variabel independen dan dependen hanya satu kali pada satu saat (Nursalam, 2013).

Teknik pengambilan sampel menggunakan metode proportional sampling yaitu teknik pengambilan sampel yang memperhatikan pertimbangan unsur-unsur dalam kategori di dalam populasi penelitian. Dalam penelitian ini diambil dari kelas dua sampai kelas enam. Berdasarkan perhitungan maka jumlah sampel yang dibutuhkan yaitu 30 siswi.

\section{HASIL DAN PEMBAHASAN}

1. Umur

Tabel 1. Distribusi Frekuensi Umur siswi di SDN Bulangan Branta Pegantenan Kabupaten Pamekasan 2019

\begin{tabular}{|c|c|c|}
\hline Umur & Frekuensi & Persentase \\
\hline 8 tahun & 2 & 7 \\
\hline 9 tahun & 4 & 13 \\
\hline 10 tahun & 16 & 53 \\
\hline 11 tahun & 6 & 20 \\
\hline 12 tahun & 2 & 7 \\
\hline Total & 30 & 100 \\
\hline
\end{tabular}


Berdasarkan tabel 1 dapat dilihat bahwa sebagian besar umur siswi kelas 2-6 yaitu berusia 10 tahun sebanyak 16 siswi $(53 \%)$.

\section{Jumlah Siswa}

Tabel 2. Distribusi Frkuensi Jumlah Siswi di SDN Bulangan Branta Pegantenan Kabupaten Pamekasan 2019

\begin{tabular}{lcc}
\hline Kelas & Frekuensi & Persentase \% \\
\hline Dua & 8 & 27 \\
Tiga & 8 & 27 \\
Empat & 8 & 27 \\
Lima & 5 & 17 \\
Enam & 1 & 3 \\
\hline Total & $\mathbf{3 0}$ & $\mathbf{1 0 0}$ \\
\hline
\end{tabular}

Sumber: Data Primer Peneliti, Tahun 2019

Berdasarkan tabel 2 dapat dilihat bahwa sebagian kecil jumlah siswi kelas dua, tiga, dan empat yaitu sebanyak 8 siswi (27\%).

\section{Tingkat Pendidikan}

Tabel 3 Distribusi Frekuensi Tingkat Pendidikan Ibu pada siswi di SDN Bulangan Branta Pegantenan Kabupaten Pamekasan 2019

\begin{tabular}{lcc}
\hline $\begin{array}{l}\text { Tingkat } \\
\text { Pendidikan } \\
\text { Ibu }\end{array}$ & Frekuensi & Persentase \\
\hline Tinggi & & \\
Menengah & 1 & $\mathbf{3}$ \\
Dasar & 3 & 10 \\
\hline Total & 26 & 87 \\
\hline Sotal & $\mathbf{3 0}$ & $\mathbf{1 0 0}$ \\
\hline
\end{tabular}

Sumber: Data Primer Peneliti, Tahun 2019

Berdasarkan tabel 3 menunjukan

bahwa ada sebagian kecil 1 ibu (3\%) berpendidikan Tinggi dan 3 ibu (10\%) berpendidikan Menengah, sementara hampir seluruh tingkat pendidikan ibu adalah berpendidikan dasar yaitu sebanyak 26 orang (87\%). Firdaus dalam Jerfriyanto (2015) menyebutkan bahwa rendahnya minat orang tua untuk melanjutkan pendidikan di sebabkan faktor sosial budaya, kurangnya biaya pendidikan ekonomi tidak mumpuni, kurangnya tingkat kesadaran orang tua akan pentingnya pendidikan serta letak geografis sekolah membuat akses pendidikan sulit terjangkau, kurangnya SDM yang memadai juga menjadi faktor pemicu terhambatnya pendidikan di pedesaan. Mengingat pendidikan hal yang mutlak dan penting bagi kamajuan dan kesejahteraan masyarakat pedesaan. Maka perlu dilakukan secara intensif dengan memberikan kesempatan seluas luasnya kepada mereka.

\section{Personal Higiene}

Tabel 4. Distribusi Frekuensi Personal Hygiene pada siswi di SDN Bulangan Branta Pegantenan Kabupaten Pamekasan 2019

\begin{tabular}{lcc}
\hline $\begin{array}{l}\text { Pesonal } \\
\text { Hygiene }\end{array}$ & Frekuensi & $\begin{array}{l}\text { Persentase } \\
(\%)\end{array}$ \\
\hline Baik & 7 & 23 \\
Cukup & 9 & 30 \\
Kurang & 14 & 47 \\
\hline Total & $\mathbf{3 0}$ & $\mathbf{1 0 0}$ \\
\hline
\end{tabular}

Sumber: Data Primer Peneliti, Tahun 2019

Berdasarkan tabel 4 menunjukan bahwa hampir setengahnya personal hygiene siswi yaitu kurang baik sebanyak 14 orang (47\%). Atikah dalam Ni'mah (2016) berpendapat bahwa personal hygiene merupakan tindakan untuk memelihara kebersihan dan kesehatan seseorang untuk kesejahteraan fisik dan psikis dari ujung rambut sampai ujung kaki. Personal hygiene diperlukan untuk meminimalkan terjangkitnya penyakit terutama yang berhubungan dengan kebersihan diri yang buruk. Kebersihan diri yang buruk akan mempermudah tubuh terserang berbagai penyakit seperti penyakit kulit dan penyakit infeksi terutama infeksi pediculosis capitis. 


\section{Kejadian Pediculosis Capitis}

Tabel 5. Distribusi Frekuensi Kejadian Pediculosis Capitis pada siswi di SDN Bulangan Branta Pegantenan Kabupaten Pamekasan 2019

\begin{tabular}{lcc}
\hline $\begin{array}{l}\text { Pediculosis } \\
\text { capitis }\end{array}$ & Frekuensi & $\begin{array}{l}\text { Persentase } \\
(\%)\end{array}$ \\
\hline Ada & 17 & 57 \\
Tidak ada & 13 & 43 \\
\hline Total & $\mathbf{3 0}$ & $\mathbf{1 0 0}$ \\
\hline
\end{tabular}

Sumber: Data Primer Peneliti, Tahun 2019

Berdasarkan tabel 5 menunjukan bahwa sebagian besar anak mengalami kejadian pediculosis capitis yaitu 17 anak (57\%).
Djuanda dkk dalam Salbiah (2018) berpendapat bahwa pediculosis capitis adalah infestasi kulit kepala yang disebabkan oleh Pediculus Humanus Capitis. Parasit ini biasanya hidup di kepala terutama kepala bagian belakang dan belakang telinga serta meletakkan telur-telurnya pada dasar tangkai rambut kepala. Parasit ini merupakan parasit obligat, artinya harus menghisap darah untuk mepertahankan hidupnya. Biasanya parasit ini menyerang anak-anak dan wanita berambut panjang.

\section{Hubungan Tingkat Pendidikan Ibu dengan Kejadian Pediculosis Capitis}

Tabel 6. Hubungan Tingkat Pendidikan Ibu dengan Kejadian Pediculosis Capitis pada Siswi di SDN Bulangan Branta Pegantenan Pamekasan 2019

\begin{tabular}{lll}
\hline Tingkat & Kejadian Pediculosis Capitis & Jumlah \\
Pendidikan Ibu &
\end{tabular}

\begin{tabular}{lccccccc} 
& \multicolumn{1}{c}{ Tidak Terjadi } & \multicolumn{3}{c}{ Terjadi } & \multicolumn{2}{c}{ Total } \\
& $\mathbf{N}$ & & $\mathbf{\%}$ & $\mathbf{N}$ & $\mathbf{\%}$ & & \\
\hline Tinggi & 1 & 100 & & 0 & 0 & 1 & $\mathbf{1 0 0}$ \\
Menengah & 3 & 100 & & 0 & 0 & 3 & $\mathbf{1 0 0}$ \\
Dasar & 9 & 34,6 & 17 & 65,4 & 26 & $\mathbf{1 0 0}$ \\
\hline Jumlah & $\mathbf{1 3}$ & $\mathbf{4 3 , 3}$ & $\mathbf{1 7}$ & $\mathbf{5 6 , 7}$ & $\mathbf{3 0}$ & $\mathbf{1 0 0}$ \\
\hline
\end{tabular}

Sumber: Data Primer Peneliti, Tahun 2019

Berdasarkan tabel 6 menunjukan bahwa ibu berpendidikan Tinggi seluruhnya (100\%) mempunyai anak yang tidak mengalami kejadian pediculosis capitis. Untuk ibu yang berpendidikan Menengah seluruhnya (100\%) mempunyai anak yang tidak mengalami kejadian pediculosis capitis. Untuk ibu yang berpendidikan Dasar hampir setengahnya $(34,6 \%)$ tidak mempunyai anak yang mengalami kejadian pediculosis capitis, sementara sebagian besar ibu $(65,4 \%)$ mempunyai anak yang mengalami kejadian pediculosis capitis
Dari hasil analisis dengan menggunakan uji koefisien kontigensi lambda dengan menggunakan SPSS 16 for windows didapatkan nilai $\mathrm{p}=0,32<0,05$. Dengan demikian dapat disimpulkan bahwa Ho ditolak Ha diterima yang berarti terdapat hubungan tingkat pendidikan ibu dengan kejadian pediculosis capitis pada siswi di SDN Bulangan Branta Pegantenan Kabupaten Pamekasan Madura.

Mansjoer dalam Jefrianto berpendapat bahwa pendidikan secara umum adalah segala upaya yang direncanakan untuk mempengaruhi orang lain baik individu, 
kelompok, atau masyarakat sehingga mereka pendidikan, karena pendidikan merupakan suatu usaha untuk membantu individu, keluarga atau masyarakat dalam meningkatkan kemampuan atau perilaku untuk mencapai pengetahuan secara optimal. Pendidikan adalah adalah suatu usaha untuk mengembangkan kepribadian serta kemampuan di dalam dan di luar sekolah dan melakukan apa yang di harapkan oleh pelaku berlangsung seumur hidup. Pendidikan mempengaruhi proses belajar, makin tinggi pendidikan seseorang makin semakin mudah orang tersebut menerima informasi, makin banyak informasi yang diterima semakin banyak pula pengetahuan yang didapat tentang kesehatan.

7. Hubungan Personal Hygiene dengan Kejadian Pediculosis Capitis

Tabel 7. Hubungan Personal Hygiene dengan kejadian Pediculosis Capitis pada Siswi di SDN Bulangan Branta Pegantenan Kabupaten Pamekasan 2019

\begin{tabular}{|c|c|c|c|c|c|c|}
\hline \multirow{3}{*}{$\begin{array}{l}\text { Personal } \\
\text { Hygiene }\end{array}$} & \multicolumn{5}{|c|}{ Kejadian Pediculosis Capitis } & \multirow{2}{*}{$\begin{array}{c}\text { Jumlah } \\
\text { Total }\end{array}$} \\
\hline & \multicolumn{2}{|c|}{ Tidak Terjadi } & \multicolumn{2}{|c|}{ Terjadi } & \multirow[b]{2}{*}{$\mathbf{N}$} & \\
\hline & $\mathbf{N}$ & $\%$ & $\mathbf{N}$ & $\%$ & & $\%$ \\
\hline Baik & 7 & 100 & 0 & 0 & 7 & 100 \\
\hline Cukup & 3 & 33,3 & 6 & 66,7 & 9 & 100 \\
\hline Kurang & 3 & 21,4 & 11 & 78,6 & 14 & 100 \\
\hline Jumlah & 13 & 43,3 & 17 & $\mathbf{5 6 , 7}$ & 30 & 100 \\
\hline
\end{tabular}

Sumber: Data Primer Peneliti, Tahun 2019

Berdasarkan tabel 7 diperoleh data bahwa anak yang mempunyai personal hygiene baik, seluruhnya (100\%) tidak terjadi pediculosis capitis. Untuk anak yang mempunyai personal hygiene cukup, hampir setengahnya $(33,3 \%)$ tidak terjadi pediculosis capitis, sementara sebagian besar siswi $(66,7 \%)$ mengalami kejadian pediculosis capitis. Sedangkan anak yang mempunyai personal hygiene kurang, sebagian kecil $(21,4 \%)$ siswi tidak terjadi pediculosis capitis, sementara hampir seluruh siswi $(78,6 \%)$ mengalami kejadian pediculosis capitis.

Dari hasil analisis dengan menggunakan uji koefisien kontigengsi lambda dengan menggunakan SPSS 16 for windows didapatkan nilai $\mathrm{p}=0.003<0,05$. Dengan demikian dapat disimpulkan bahwa Ho ditolak Ha diterima yang berarti terdapat hubungan personal hygiene dengan kejadian pediculosis capitis pada siswi di SDN Bulangan Branta Pegantenan Kabupaten Pamekasan Madura.

Potter dan Perry dalam Hapsari (2019) berpendapat bahwa personal hygiene yang kurang merupakan faktor utama yang mempermudah infeksi masuk ke anggota tubuh baik kulit kepala dan rambut maupun anggota badan lainnya pada tubuh manusia. Pediculus capitis merupakan penyakit infeksi kulit kepala dan rambut yang disebabkan oleh pediculus humanus capitis yang mana penderita kurang meperhatikan personal hygiene nya, hal ini sangat memprihatinkan, karena infeksi ini sebenarnya dapat di cegah dengan meningkatkan kualitas personal hygiene setiap individu. Dari analisa di atas menunjukan bahwa menjaga personal hygiene baik langsung maupun tidak langsung pada 
penderita pediculosis capitis merupakan salah satu cara pencegahan terbaik dari pada mengobati terjadinya pediculosis capitis. Akibat dari infeksi pediculosis capitis yang tidak diobati dapat menimbulkan berbagai dampak pada penderitanya, antara lain berkurangnya kualitas tidur anak pada malam hari akibat rasa gatal, stigma sosial, rasa malu dan rendah diri.

\section{KESIMPULAN}

1. Siswi hampir seluruhnya mempunyai ibu berpendidikan rendah sebanyak $87 \%$ di SDN Bulangan Branta Pegantenan Kabupaten Pamekasan Madura.

2. Siswi setengahnya mempunyai personal hygiene yang kurang sebanyak $47 \%$ di SDN Bulangan Branta Pegantenan Kabupaten Pamekasan Madura.

3. Siswi sebagian besar mengalami kejadian pediculosis capitis sebanyak $57 \%$ di SDN Bulangan Branta Pegantenan Kabupaten Pamekasan Madura.

4. Ada hubungan antara tingkat pendidikan ibu dengan kejadian pediculosis capitis pada siswi di SDN Bulangan Branta Pegantenan Pamekasan Madura.

5. Ada hubungan personal hygiene dengan kejadian pediculosis capitis pada siswi di SDN Bulangan Branta Pegantenan Pamekasan Madura.

\section{SARAN}

1. Bagi institusi kesehatan

Sebaiknya instansi kesehatan terdekat untuk meningkatkan penyuluhan tentang upaya pencegahan kejadian pediculosis capitis pada anak.

2. Bagi masyarakat / ibu
Diharapkan masyarakat terutama ibu menjadi lebih aktif dalam mencari informasi mengenai pencegahan kejadian pediculosis capitis.

3. Bagi peneliti

Diharapkan pada penelitian yang lebih detail dan mendalam dengan jumlah responden yang lebih banyak tentang hubungan tingkat pendidikan ibu dan personal hygiene dengan kejadian pediculosis capitis.

\section{DAFTAR PUSTAKA}

Hapsari, A. I. 2017. Personal Hygiene Rambut Terhadap Pediculosis Capitis Berdasarkan Karakteristik Demografinya. Seminar Nasional Biologi, IPA dan Pembelajarannya. UM Jember.

Jeffriyanto, E. B. 2013. Hubungan Usia Dan Tingkat Pendidikan Ibu DenganTindakan Pencegahan Penyakit Pneumonia Di Rw 1 Rt 1 Kelurahan Bancaran Kecamatan Bangkalan Kabupaten Bangkalan. Skripsi. Bangkalan: Program Studi Ilmu Keperawatan Sekolah Tinggi Ilmu Kesehatan Insan Se Agung Bangkalan

Karimah, A et al . 2016. Prevalence And Predisposing Factors Of Pediculosis Capitis On Elementary School At Jatinangor. Althea Medical Journal

Kamus Bahasa Indonesia. 2008. https://kbbi.web.id/didik di akses 29 November 2018

Nindia, Y. 2016. Prevalensi Infestasi Kutu Kepala (Pediculus Humanus Capitis) Dan Faktor Risiko Penularannya Pada Anak Sekolah Dasar Di Kota Sabang Provinsi Aceh. Skripsi. Bogor: Institut Pertanian Bogor.

Ni'mah, N. 2016. Hubungan Perilaku Personal Hygiene Dengan Kejadian Scabies Pada Santri Putra Dan Putri Di Pondok Pesantren An-Nur Ngrukem Sewon Bantul Yogyakarta. Program Studi Ilmu Keperawatan 
Fakultas Ilmu Kesehatan Universitas 'Aisyiyah Yogyakarta.

Nursalam, 2013. Metodologi Penelitian Ilmu Keperawatan. Jakarta: Salemba Medika

Pemerintah Nasional. 2012. Undang-undang RI Nomor 12 tahun 2102. Jakarta: Sekretariat Negara

Salbiah. 2018. Perilaku Yang Berhubungan Dengan Pediculosis Capitis Pada Pada Siswi Madrasah Tsanawiyah Hifzil Quran Medan. Jurnal Ilmu Dan Teknologi Kesehatan. Vol 5 No 2
Zulinda, A et al. 2010. Faktor-Faktor Yang Mempengaruhi Kejadian Pediculosis Capitis Pada Murid Kelas. III, IV, V, Dan VI SDN 019 Tebing Tinggi Okura Kecamatan Rumbai Pesisir Pekanbaru. Jurnal Ilmu Kedokteran 